\title{
Effect of the Addition of Different Amounts of Nanosilica on Tmos/Pdms Hybrid Coating for Marble
}

\author{
Gözde Tekin Eroğul ${ }^{1}$, Onuralp Yücel ${ }^{2}$, Gamze Gül Avcı $^{3}$, Ceyda Zeynep Koyuncu ${ }^{4}$ \\ M.S.C., Materials Institute, TUBITAK Marmara Research Center, Kocaeli, Turkey ${ }^{1}$ \\ Prof. Dr., Istanbul Technical University, Istanbul, Turkey ${ }^{2}$ \\ M.S.C., Materials Institute, TUBITAK Marmara Research Center, Kocaeli, Turkey ${ }^{3}$ \\ Dr., Materials Institute, TUBITAK Marmara Research Center, Kocaeli, Turkey ${ }^{4}$
}

\begin{abstract}
Marbles are usually hydrophilic, and have contact angle values between $40-60^{\circ} \mathrm{C}$. This makes marble surfaces susceptible to attack from water, which is the main instigator of stone decay causing salt crystallization inside the pores of the stone. Alkoxysilanes are widely used in the protection of stones such as marbles, granites or limestones. Nevertheless, gels made of alkoxysilanes are not always hydrophobic. In this research, we imparted hydrophobic character into the marbles by the addition of polydimethysiloxane, and further improved this hydrophobicity by adding different amounts of $(\% 0,1, \% 1, \% 3, \% 5 \mathrm{w} / \mathrm{w})$ nanosilica with respect to the alcohol content. We measured the contact angle values of the coated marble samples and corrolated these results with AFM measurements, and SEM images. We exposed the coated samples humidity, and UV aging tests to evaluate the protective efficiency of the coatings.
\end{abstract}

Keywords: Nanosilica, Contact Angle, Sol-Gel, Hydrophobic, Marble

\section{INTRODUCTION}

Natural stones, such as marbles, are one of the most significant parts of our cultural heritage that should be preserved and passed on to future generations. Nevertheless, natural stones are continuously weathered due to atmospheric effects such as rain, wind and atmospheric gases. For this reason, protective coatings should be developed to prevent natural stones from decaying.

Water is one of the most significant causes of stone decay because it enables weathering due to atmospheric pollutants, causes disintegration inside and on the surface of the stone, cracking through freezing-thawing or wetting-drying cycles and salt crystallization inside the pores. Morever, water asists in the growth of microorganisms and the formation of crusts. Because of this, it is of paramount importance to develop hydrophobic coatings for surface protection [1].

Using hydroxylterminated polydimethylsiloxane as an additive in alcoxysilane based sol-gel systems can be used as a method to develop hydrophobic coatings. This is due to the reduction of the surface tension of the coating with the incorporation of PDMS [2]. Coatings involving only alcoxysilanes are usually hydrophilic [3], where as polydimethylsiloxane incorporated alcoxysilane based sol-gel sytems have a contact angle about $100-110^{\circ}$ [4]. Apart from hydrophobicity, adding polymethyldisiloxane into the TEOS matrix also has additional advantages such as its ability to penetrate into the stone because of its low viscosity ( $4 \mathrm{mPas})$, to form siloxane bonds, to preserve the color of the stone, and to prevent gel cracking because of its flexibility resulting from the methyl groups at each end of the silicon atom [5].

Besides adding hydroxylterminated polydimethylsiloxane as an additive in alcoxysilane based sol-gel systems, implementation of nanosilica can also be used as a method to improve hydrophobicity. Nanosilica can be added in the form of aqueous colloidal dispersions or powders. Maravelaki-Kalaitzaki et. al. and Salazar- Hernandez added colloidal silica to TEOS based formulations [6,7]. $\mathrm{Li}$ et. al added nanosilica powder $(0.1,0.2,0.4 \% \mathrm{w} / \mathrm{v})$ to sols containg TEOS, ethanol, and PDMS, and observed that the addition of silica nanoparticles at $0.1 \%(\mathrm{w} / \mathrm{v})$ increased the surface roughness and hydrophobicity [8]. Similary, Manoudis et. al. added silica nanoparticles $(7 \mathrm{~nm}$.) to the commercial polyalkylsiloxane Rhodorsil 224, and observed that the treated stone surfaces exhibited superhydrophobic properties [9]. In this study, we added different amounts of nanosilica $(0.1,1,3,5 \% \mathrm{w} / \mathrm{w})$ to the TMOS/PDMS-OH hybrid sol, and used AFM and SEM techniques to investigate how the contact angle of a TMOS/PDMS-OH protective coating is influenced by the addition of different amounts of nanosilica. We also exposed the coated marbles to UV aging, and 


\title{
International Advanced Research Journal in Science, Engineering and Technology
}

\author{
Vol. 6, Issue 2, February 2019
}

humidity tests to evaluate the protective efficiency of the coatings. We measured the contact angle values of the coatings, before and after the humidity test, and also the colorimetric properties of the coatings before, and after the UV tests to find out the effect of the coatings on the optical appearance of the marbles, and compared these results with the commercial Silres BS 290 solution.

\section{EXPERIMENTAL}

\section{A. Materials}

1) Chemical Reagents: TMOS, which is an analytical grade reagent, was obtained from Fluka Chemical AG, PDMS-OH $(\mathrm{Mw}=500-750)$, and $\mathrm{HCl}(\% 37)$ was purchased from Sigma Aldrich. Aerosil R972, whose declared average size is $16 \mathrm{~nm}$, was purchased from Evonik. Silres BS 290 is a hydrophobic product purchased from Wacker Chemie AG. It is a solventless silicone concentrate that is based on silane/siloxane and is dilutable with organic solvents [10]. Silres BS 290 was dilluted in white spirit (\%7) before it was used.

2) Stone Materials: Marble samples were collected from a marble quarry named Koçar in a Turkish city called Muğla to be representative of historical monuments nearby. Then, they were cut to cylindrical samples of $\varnothing \sim 2.5$ $\mathrm{cm}$, and $\mathrm{h} \sim 1 \mathrm{~cm}$. by the waterjet technique. The polished surface was ripped of using coarse sandpaper. Before treatment, the marbles were wiped with paper towel saturated with water, and dried in an oven at $110^{\circ} \mathrm{C}$ to constant weight.

\section{B. Preperation of Sols}

4 sols were prepared with varying amounts of PDMS (\%0.1, \%1, and \%3, and \%5). Commercial Silres BS 290 (\%7 $\mathrm{w} / \mathrm{v}$ in white spirit) was used for comparison purposes. At first, $3.5 \mathrm{gr}$ of TMOS and $1.7 \mathrm{gr}$ of acidified water ( $\mathrm{pH}=4)$ and $1.85 \mathrm{gr}$ of methanol was refluxed at $70^{\circ} \mathrm{C}$ for 2 hours. Then, PDMS, and nanosilica dispersed in isopropanol $(\% 0.1,1,3 \mathrm{w} / \mathrm{w})$ was added to this sol. After that, ultrasonic agitation of the sol was performed for $30 \mathrm{~min}$, and the sol was magnetically stirred at $400 \mathrm{rpm}$ overnight.

\section{Coating of Marble Samples}

The $\% 0.1,1,3$ and $\% 5 \mathrm{w} / \mathrm{w}$ sols were coated on marble samples using the dipcoater. The withdrawal speed was 15 $\mathrm{cm} / \mathrm{min}$. Then, commercial Silres BS290 was dilluted in white spirit (\%7 w/w), and coated on another marble sample for comparison.

\section{Methods of Characterization}

1) $X R D$ and $X R F$ Analysis: Phase characterizations of samples were carried out by using Shimadzu ${ }^{\mathrm{TM}} \mathrm{XRD}-6000$ $\mathrm{X}$-ray diffractometer in the $2 \theta$ range of $2-70^{\circ}$ with the step size of $0.02^{\circ}$ using a $\mathrm{Cu}$ radiation tube (wavelength $1.5405 \AA$ ). The chemical compositions were carried out on a Philips PW2404 XRF spectrometer, equipment with rhodium tube (wavelength $0.613 \AA$ ).

2) Contact Angle Values: Water contact angle measurements were conducted using distilled water and a Krüss DSA 100 contact angle measuring instrument. Three droplets of water were delivered to different points of each specimen and from a height sufficiently close to the substrate, so that the needle remained in contact with the water droplet. After 30 seconds, the delivery needle was withdrawn [11]. The static contact angle was calculated by the sessile drop method. The reported contact angle values are average values of three measurements.

3) Scanning Electron Microscopy (SEM): The surface morphologies of the coated marbles were studied using a Quanta FEG-250 ESEM enviromental scanning electron microscope at $20 \mathrm{kV}$ of voltage, and elemental analysis was performed with INCA EDS at $10 \mathrm{keV}$.

4) Colorimetric Measurements: The effect of the coating on the optical appearance of the marbles was evaluated with colorimetric measurements using a Digieye Color Measurement System. Three measurements were taken from the uncoated, and the coated parts of the marble samples before, and after the UV aging test. The results were evaluated by the use of $\mathrm{L}^{*} \mathrm{a}^{*} \mathrm{~b}^{*}$ coordinates of the CIE Lab scale [12]. All the given results are average values from 3 measurements on each specimen.

5) AFM Measurements: AFM samples have been investigated by Quesant Ambios Technology Inc. Qscope250 $(80 \mu \mathrm{m} \times 80 \mu \mathrm{m}$ scan size) at a scan rate of $1 \mathrm{~Hz}$. Intermittent Wavemode mode (with Ambios Non-Contact NSC16 Silicon Cantilever) has been used for $10 \mu \mathrm{m}$ x $10 \mu \mathrm{m}$ scan areas. ScanAtomic V5.0.0 SPM Control software was used for imaging. 


\section{International Advanced Research Journal in Science, Engineering and Technology}

Vol. 6, Issue 2, February 2019

6) Optical Microscopy Analysis: The samples subjected to 96 hour humidity test were analyzed by Nikon Eclipse L150 optical microscope at 10x.

\section{E. Evaluation of The Protective Efficiency of The Coatings}

1) Humidity Test: The samples were subjected to humidity tests according to ISO 6270-2 in a humidity cabinet at a temperature of $40^{\circ} \mathrm{C}$, and $\% 100 \mathrm{RH}$ for a total of 96 hours [13]. Then, the samples were dried at $110^{\circ} \mathrm{C}$ in a Heraus air oven for 4 hours, and the static contact angles of the samples were measured with a Kruss DSA 100 drop shape analyzer.

2) UV Aging Test: The coated samples were subjected to a 144 hour UV test at a black standard temperature of $60^{\circ} \mathrm{C}$, and $555 \mathrm{~W} / \mathrm{m}^{2}$ radiation intensity with a UV filter with a Suntest CPS+ apparatus equipped with a Xenon Arc lamp. The colorimetric values were measured before and at the end of the test.

\section{RESULTS}

A. XRD and XRF Analysis

The XRD, and XRF analysis of the marbles showed that the composition of the marbles was \%99 calcite, with trace amounts of quartz, and clay.

\section{B. Water Contact Angle}

The static water contact angle (SCA) on the untreated marbles was $60^{\circ}$. Hydrophobization of marble surface with PDMS, and the addition of $\% 0.1 \mathrm{w} / \mathrm{w}$ silica nanoparticles increased the hydrophobicity of the surface to $95^{\circ}$, and this trend continued till $\% 1 \mathrm{w} / \mathrm{w}$ silica nanoparticles at $145^{\circ}$. Nevertheless, further addition slightly reduced the contact angle. Contact angle values of $140^{\circ}$, and $135^{\circ}$ were obtained for the coatings with $\% 3$, and $\% 5$ w/w coatings, respectively.
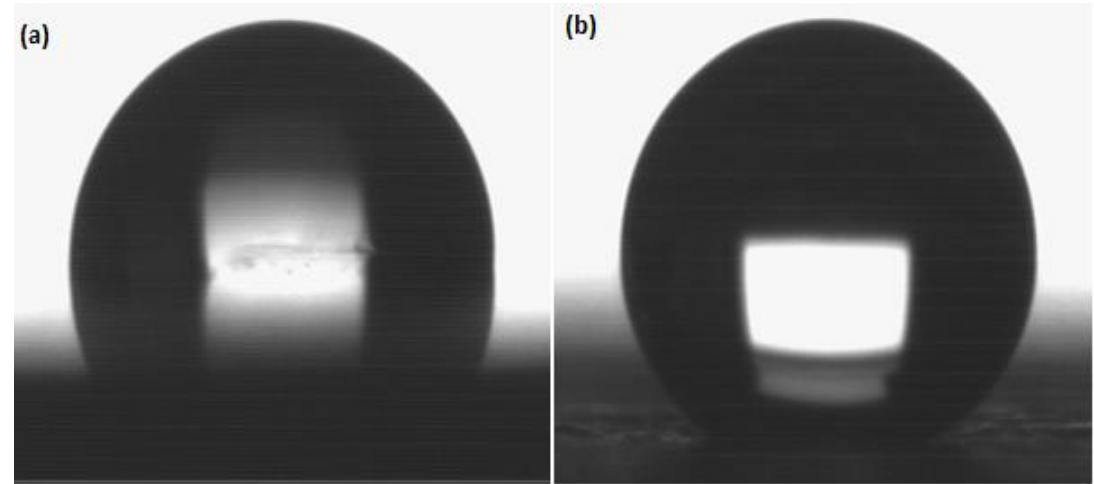

(c)

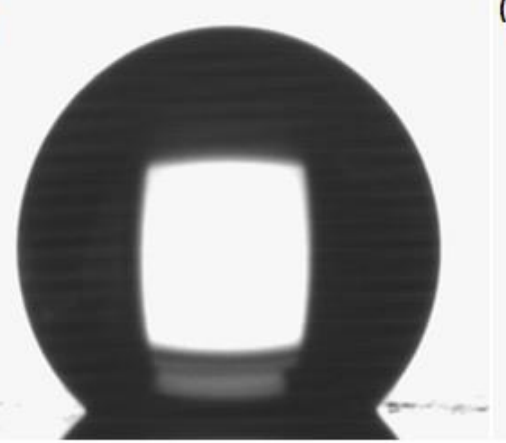

(d)

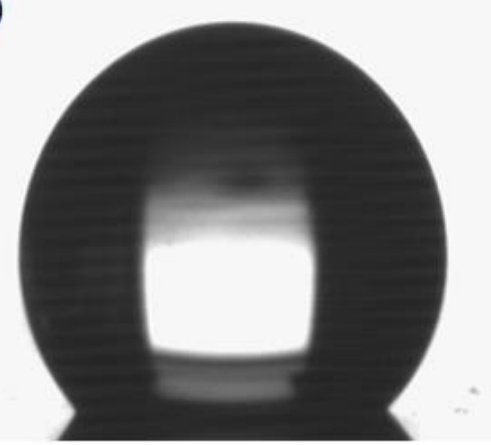

Fig. 1 Images of water droplets on (a) $\% 0.1 \mathrm{w} / \mathrm{w}$ nanosilica coated sample (b) $\% 1 \mathrm{w} / \mathrm{w}$ nanosilica coated sample (c) $\% 3 \mathrm{w} / \mathrm{w}$ nanosilica coated sample (d) $\% 5 \mathrm{w} / \mathrm{w}$ nanosilica coated sample

The change in the contact angle depending on the \% weight of the nanosilica addition was explained based on the AFM measurements, and roughness profiles. 


\section{International Advanced Research Journal in Science, Engineering and Technology}

Vol. 6, Issue 2, February 2019

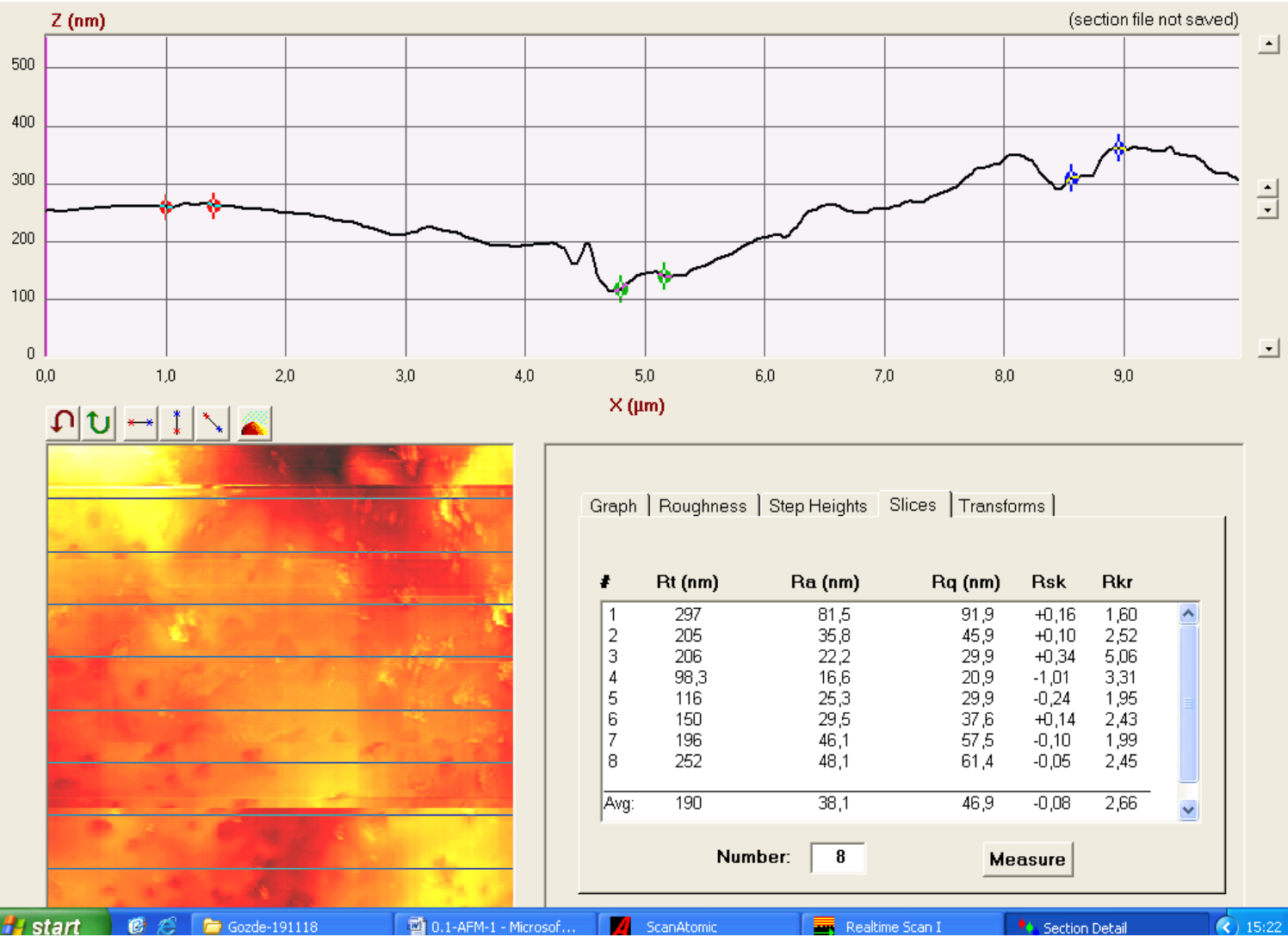

Fig. 2 AFM roughness profile of the $\% 0.1 \mathrm{w} / \mathrm{w}$ nanosilica coated samples with a scan area of $10 \times 10 \mu \mathrm{m}$

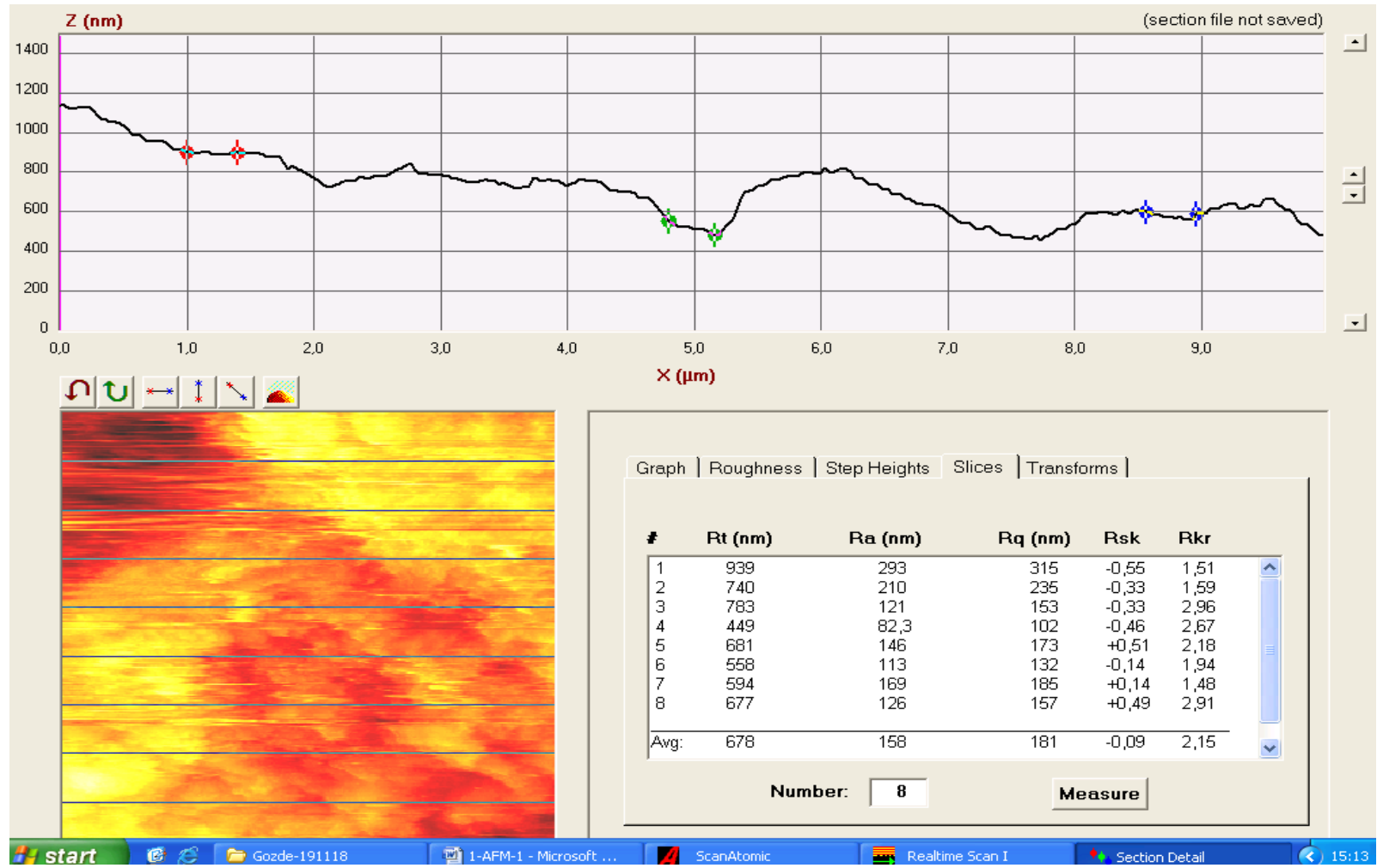

Fig. 3 AFM surface roughness profile of the $\% 1 \mathrm{w} / \mathrm{w}$ nanosilica coated samples with a scan area of $10 \mu \mathrm{m}$ 


\section{International Advanced Research Journal in Science, Engineering and Technology}

Vol. 6, Issue 2, February 2019
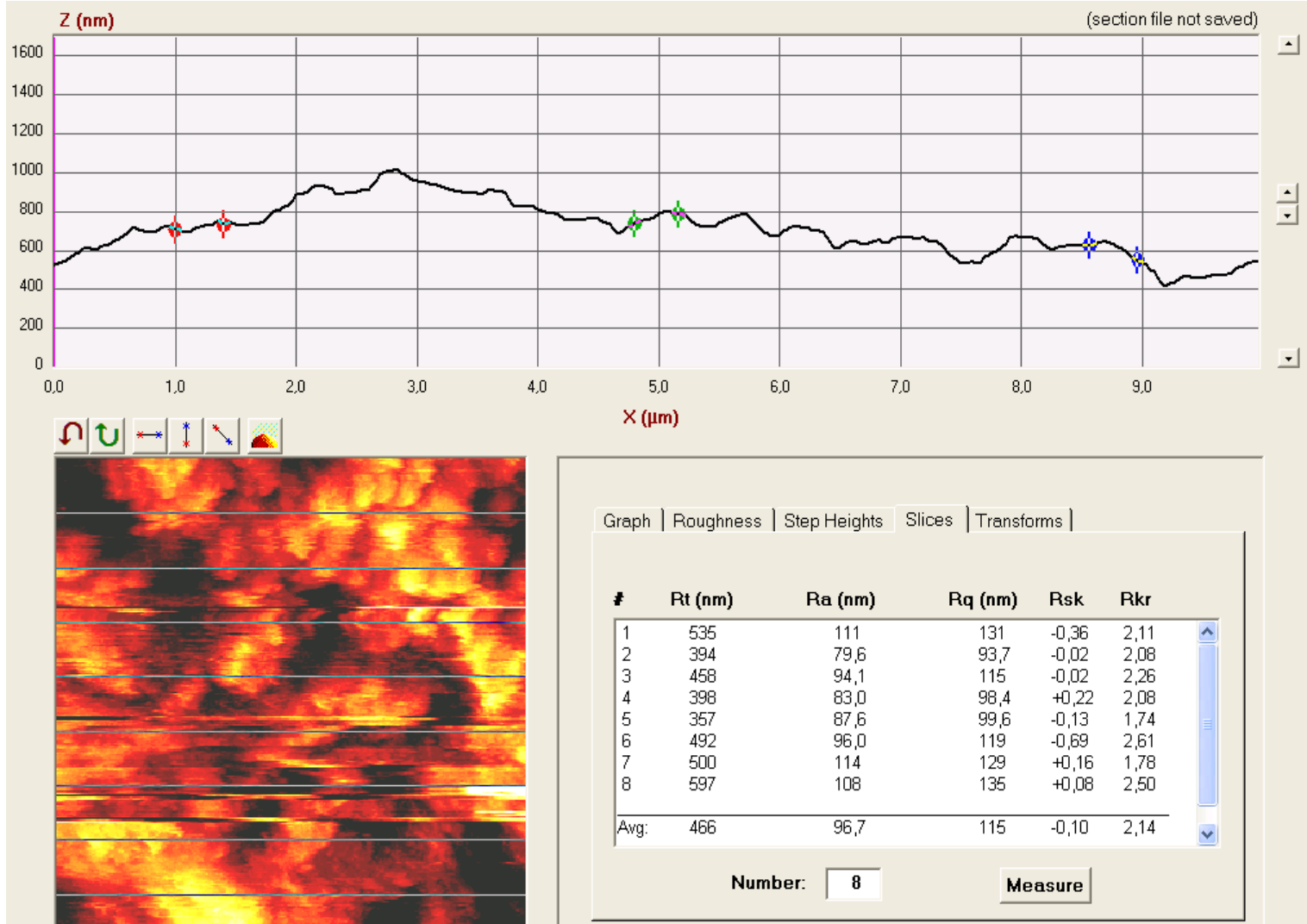

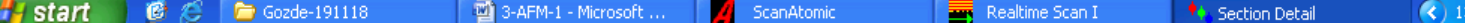

Fig. 4 AFM roughness profile of the $\% 3 \mathrm{w} / \mathrm{w}$ nanosilica coated samples with a scan area of $10 \times 10 \mu \mathrm{m}$

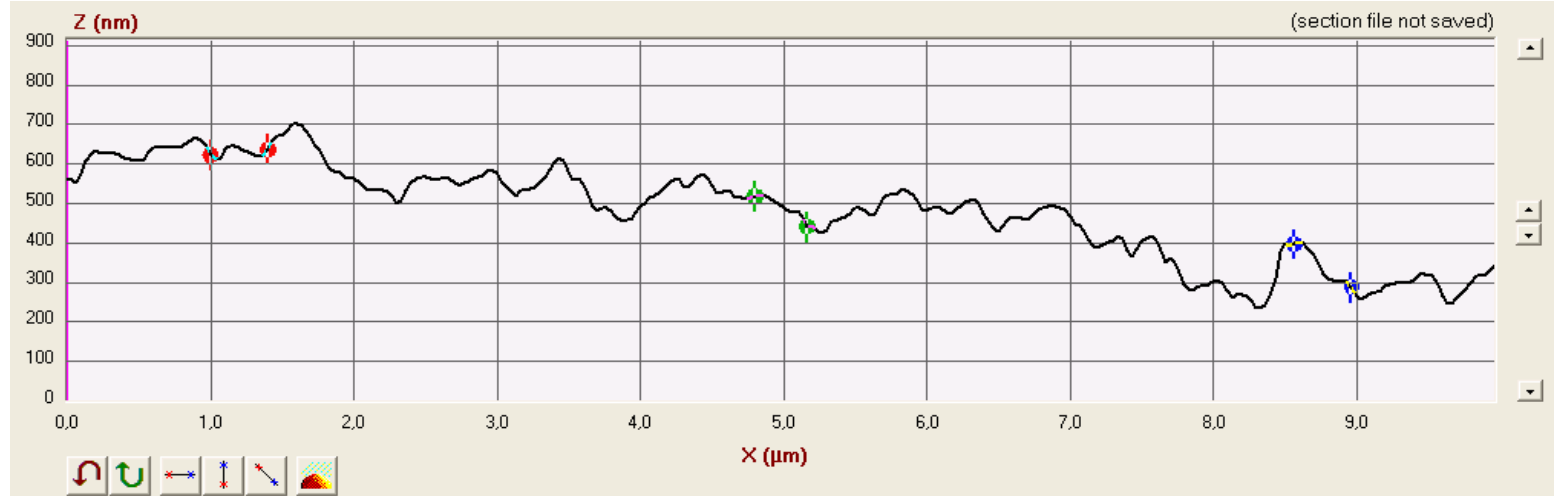

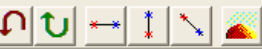

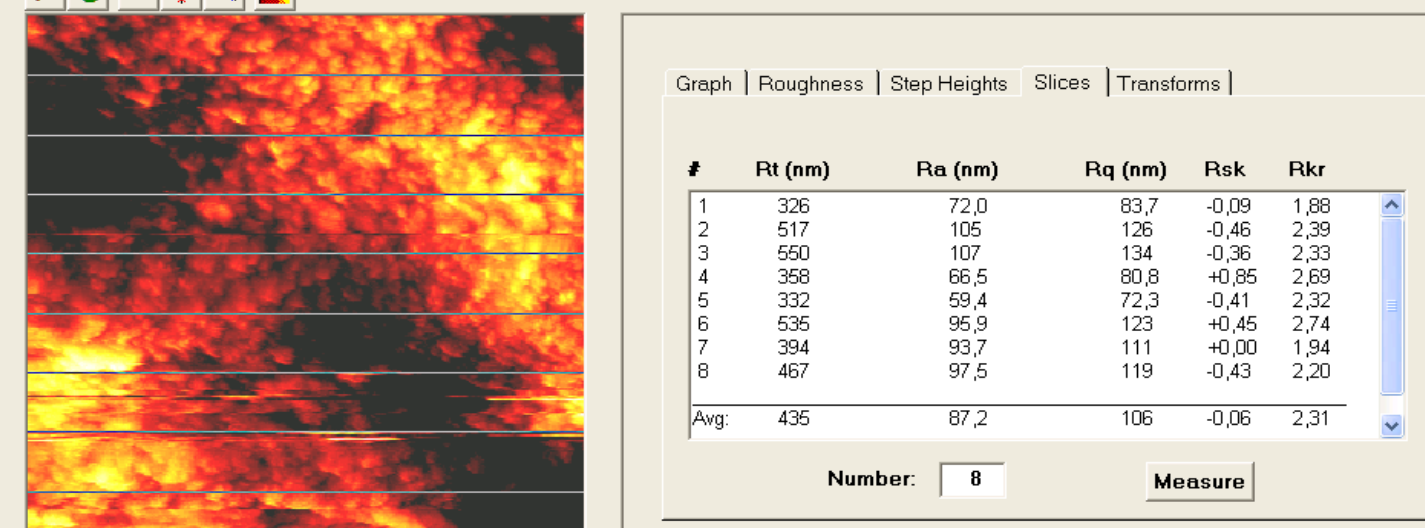

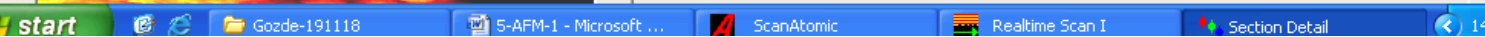

Fig. 5 AFM roughness profile of the $\% 5 \mathrm{w} / \mathrm{w}$ nanosilica coated samples with a scan area of $10 \times 10 \mu \mathrm{m}$ 


\title{
International Advanced Research Journal in Science, Engineering and Technology
}

\author{
Vol. 6, Issue 2, February 2019
}

The lowest mean roughness value is seen with the $\% 0.1 \mathrm{w} / \mathrm{w}$ nanosilica coating with an $\mathrm{R}_{\mathrm{a}}$ value of $38.1 \mathrm{~nm}$, with a contact angle value of $95^{\circ}$. When the nanosilica content is increased up to $\% 1 \mathrm{w} / \mathrm{w}$, the $\mathrm{R}_{\mathrm{a}}$ value increases up to 158 $\mathrm{nm}$, which is the highest rougness value obtained for all of the samples along with the highest contact angle value of $145^{\circ}$. Further addition seemed to reduce the roughness value to 96.7 , and 87.2 with $\% 3$ and $\% 5$ nanosilica addition respectively with contact angle values of $140^{\circ}$ and $135^{\circ}$. These results suggest that the obtained contact angle values are directly related to the mean average roughness $\left(\mathrm{R}_{\mathrm{a}}\right)$ values, and that the higher the roughness value, the higher the contact angle. Nevertheless, roughness values seem to increase with nanosilica addition only up to $\% 1$ w/w. Further addition of nanosilica particles seem to lower down the roughness of the coating.

\section{Surface Morphology}

The morphology of the treated marble surfaces depends on the distribution of nanoparticles in the film, as it can be seen from the SEM images (Fig. 6). When the nanosilica loading is \%0.1, the particles are very sparsely distributed, and cover only a small amount of the film, and smooth areas of the film are clearly visible, resulting in a contact angle of value of $95^{\circ}$. At $\% 1$ nanosilica the nanosilica protrusions cover almost the whole surface, since the density of the Aerosil R972 powder is very small. At this concentration, a two-length-scale roughness is observed in some places where nano silica particles (bright white dots) are sitting on top of micro aggregates (clusters of white dots), and the contact angle is increased to $145^{\circ}$ with the alteration of the surface morphology. Nevertheless, eventhough the particles cover a quite high area of the surface, nanosilica particles are not evenly distributed through the film due to the clustering of the aggregates on some regions creating larger voids between the aggregates, and the freely distributed nanosilica particles. At $\% 3 \mathrm{w} / \mathrm{w}$ nanosilica concentration a different morphology appears eventhough the micro- nano scale hieararchial structure is stil observed as in the case of nanosilica concentration. Here the aggregates are very evenly distributed in the film causing the formation of a network and the voids between the aggregates are very small. At $\% 5 \mathrm{w} / \mathrm{w}$ nanosilica concentration, we get a morphology somewhat similar to the one in the $\% 1 \mathrm{w} / \mathrm{w}$ coating. Nevertheless, instead of the freely distrubuted nanosilica particles, larger and longer voids are formed between the aggregates denoted by the dark regions in the SEM images which look like cracks.
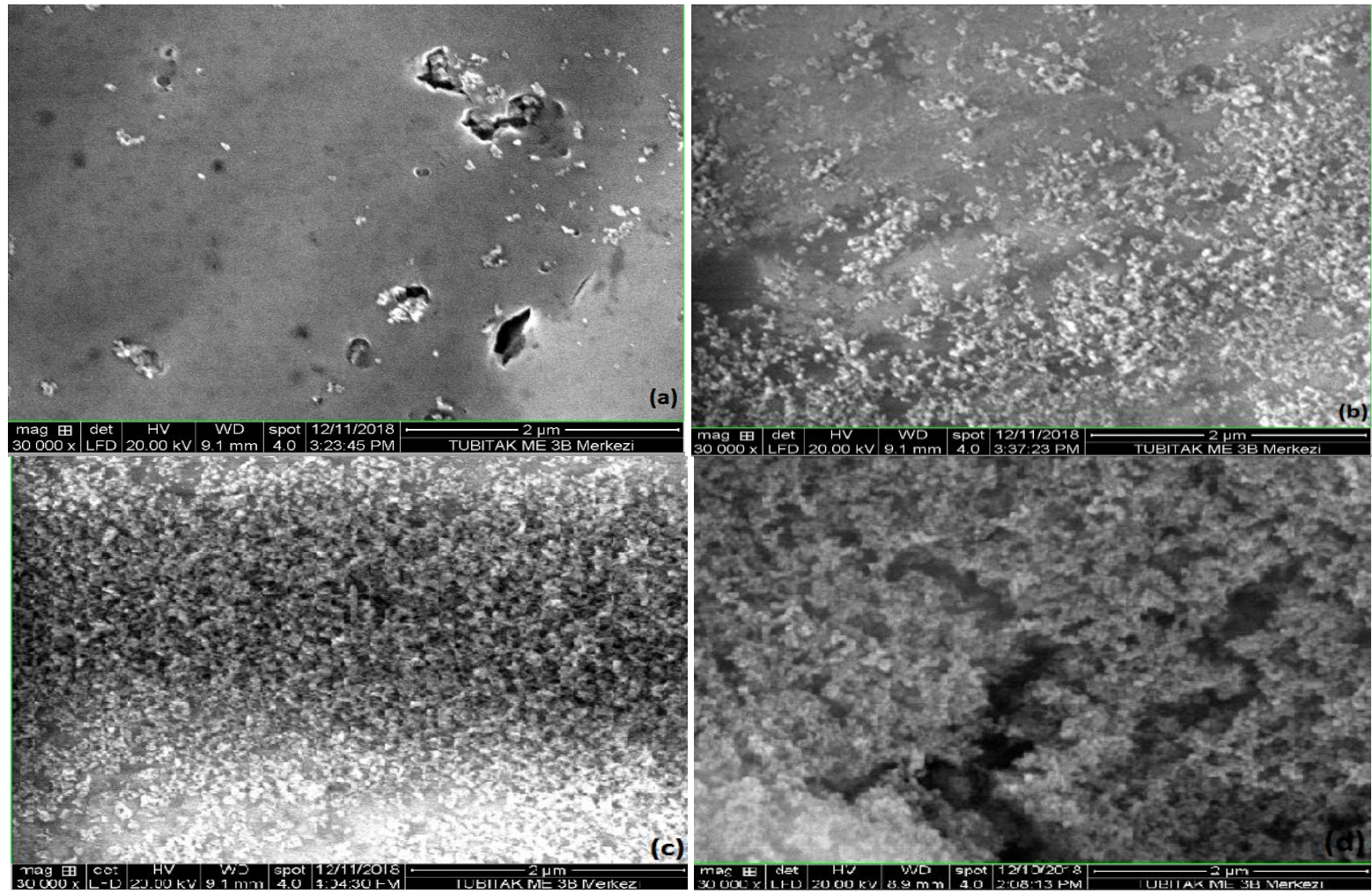

Fig. 6 SEM Images of the marble surface treated with TEOS/PDMS hybrid coating with (a) \%0.1

(b) $\% 1$, (c) $\% 3,(\mathrm{~d}) \% 5$ nanoparticles

The presence of the nanosilica particles in the coating can be verified by the EDS analysis. The Si peak tends to get sharper as the nanosilica concentration increases from $\% 1$ to $\% 3$, and $\% 3$ to $\% 5$ due to the higher amount of nanosilica particles. 


\section{International Advanced Research Journal in Science, Engineering and Technology}

Vol. 6, Issue 2, February 2019
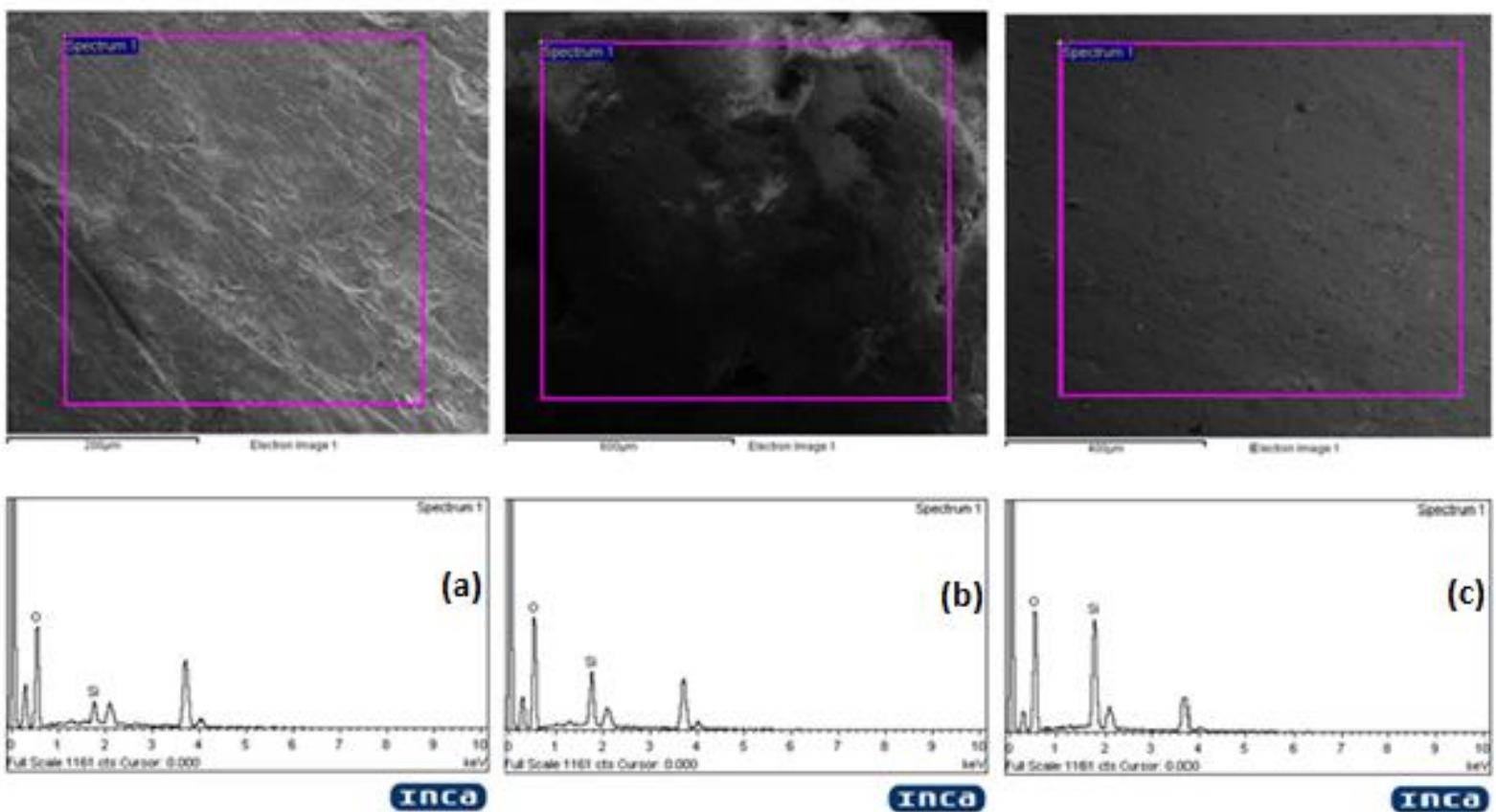

Fig. 7 EDS Analysis of a) $\% 1$ w/w nanosilica coatied marble sample b) $\% 3$ w/w nanosilica coated marble sample c) $\% 5 \mathrm{w} / \mathrm{w}$ nanosilica coated marble sample

\section{Effects of Humidity Aging}

Table I Contact Angle Values After The Humidity Test

\begin{tabular}{|c|c|}
\hline$\%$ w/w nanosilica & Contact angle values after the 96 hour humidity test \\
\hline Commercial & $95 \pm 5^{\circ}$ \\
\hline 0.1 & $90 \pm 5^{\circ}$ \\
\hline 1 & $120 \pm 5^{\circ}$ \\
\hline 3 & $140 \pm 5^{\circ}$ \\
\hline 5 & $80 \pm 5^{\circ}$ \\
\hline
\end{tabular}

The contact angle values of all samples decreased after the 96 hour humidity test except for the \%3 w/w nanosilica sample. Eventhough the contact angle values of the $\% 1$ sample was superhydrophobic before the humidity test, the contact angle value decreased to $120 \pm 5^{\circ}$. The most distinct reduction was seen in $\% 5$ sample, from $135 \pm 5^{\circ}$ to $80 \pm 5^{\circ}$, followed by the commercial coating with a reduction from $115 \pm 5^{\circ}$ to $95 \pm 5^{\circ}$, and $\% 0.1 \mathrm{w} / \mathrm{w}$ coating from $95 \pm 5^{\circ} \mathrm{C}$ to $90 \pm 5^{\circ} \mathrm{C}$. All of the coatings remained hydrophobic after the humidity test. Nevertheless, the only coating that retained its superhydrophobic properties was the $\% 3 \mathrm{w} / \mathrm{w}$ coating. This phenomenon was explained by considering the changes in the wetting behaviour of the samples, before, and after being exposed to the humidity test.

The wetting behaviour of the surfaces are usually explained by two different wetting regimes, a.k.a the Wenzel, and the Cassie Baxter regime. According to the Wenzel regime, water drops tend to fill in the grooves for rough surfaces where as for the Cassie Baxter regime, water drops sit on air pockets [14]. Before the humidity test, for the \%0.1 sample, the wetting behaviour can be explained by the Wenzel Regime. Since the distance between the nano protrusions are quiet high in this case, it is very difficult for air pockets to fill the void between the protrusions, and therefore, most of the surface is wetted, and there is a high adhesion to water molecules even though the surface is hydrophobic. In the $\% 1$ w/w nanosilica and $\% 3$ w/w nanosilica coating, however, there is a micro-nano hierarchy, when tilted the drops easily fall of the surface so the wetting behaviour coincides more with the low adhesion Cassie Baxter regime. Nevertheless, the distribution in the $\% 3 \mathrm{w} / \mathrm{w}$ nanosilica coating is much more uniform than the $\% 1$ coating creating a network formation eventhough a little bit more of the surface is covered in the $\% 1$ coating due to the freely distributed nanosilica particles which may account for the higher contact angle. In the $\% 5 \mathrm{w} / \mathrm{w}$ coating, however, the wetting state begins to transit from Cassie Baxter to Wenzel because the drops on the surface can't be easily removed which is the result of the micron sized large voids between the nanosilica clusters.

After the humidity test, however, for the \%1 coating, eventhough most of the surface is covered, and a two level hierarchy, and a high contact angle is reached, there are some regions where the cavities between the nanosilica 


\section{International Advanced Research Journal in Science, Engineering and Technology}

Vol. 6, Issue 2, February 2019

aggregates and the freely distributed nanosilica particles are large. Water vapor condenses in these cavities. Eventhough the first formed drops are spherical Cassie Baxter drops, these drops coalesce with each other and pull to the center because a droplet is sticker on the surface filled with liquid than hydrophobic smooth surface as stated by Lafuma et al., and Wier et. al. $[15,16]$, and the wide cavities between the nanostructures allow these drops to grow and transform from the non-sticky Cassie Baxter state to the sticky Wenzel state, which makes it diffcult for them to be removed resulting in the reduction of the contact angle from $145^{\circ}$ to $120^{\circ}$. In the $\% 5$ coating, we don't see much of freely distributed nanoparticles, but more so nanoparticle aggregates which are seperated by larger micro cavities throughout the film in the shape of cracks. Here, water vapor condenses into these pores, and since the area for the drops to grow is larger, we get larger areas which are wetted, and this causes the film to wet even more, resulting in the highest reduction in the contact angle, and delamination and subsequent cracking of the film. The $\% 0.1 \mathrm{w} / \mathrm{w}$ coating acts more so like a smooth film because the amount of the nanosilica particles are very low. Therefore, the contact angle stays pretty much the same before, and after the humidity test. In the \%3 coating, the cavities between the nanostructures are very small, causing a network formation. So, drops can coalesce to a very small extent. Since the drops maintain their Cassie Baxter shape, and can easily be removed when heated, which causes the contact angle value to stay unchanged after the humidity test.

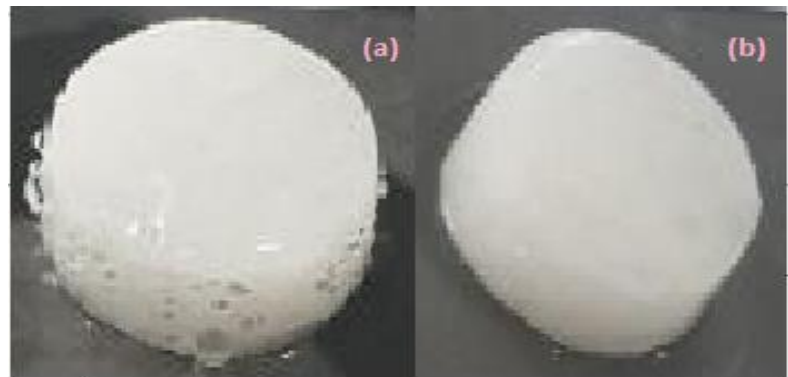

Fig. 8 a) Cassie Baxter drops of the $\% 3$ w/w coating versus b) wetted commercial coating

The cracking of the $\% 5$ nanosilica coating can be seen by the optical microscope images below:
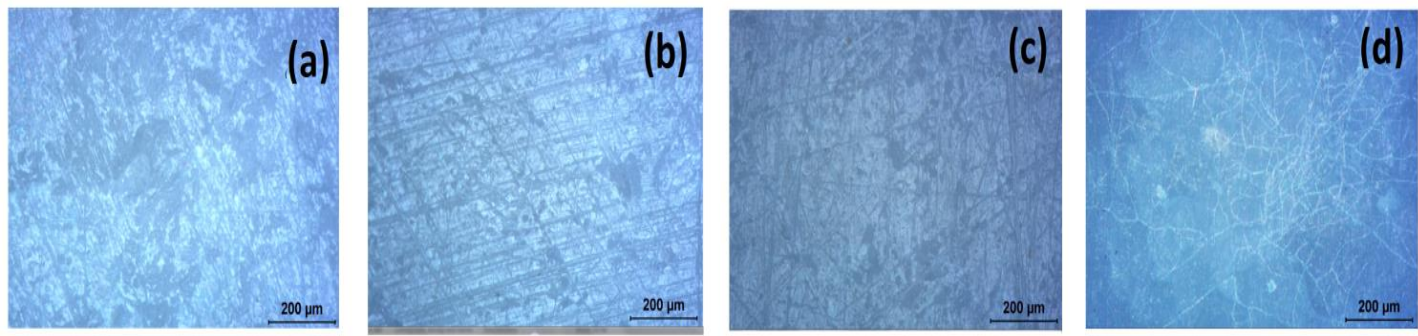

Fig. 9 Optical microscope images of a) $\% 0.1$ b) $\% 1$ c) $\% 3$ d) $\% 5$ w/w nanosilica coating

\section{E. Effects of UV Aging}

The results were evaluated as $\mathrm{L}^{*}$ (brightness), $\mathrm{a}^{*}$ (redness color), and $\mathrm{b}$ (yellowness color) coordinates. The total color difference $(\Delta \mathrm{E})$ was calculated by the following.

$$
\Delta \mathrm{E}^{*}=\sqrt{\Delta L_{a v}^{2}+\Delta a_{a v}^{2}+\Delta b_{a v}^{2}}
$$

For the calculation of the chromatic variations, one half of the marble samples were coated, and the other half was not. The uncoated parts of the marbles were selected as referance samples. L* refers to the brightness, while $a^{*}$ and $b^{*}$ to the red-green (positive for red, negative for green), and yellow-blue (positive for yellow, negative for blue)colors, respectively.

Table III Colorimetric Values Before The Uv Aging Test

\begin{tabular}{|l|l|l|l|l|l|l|l|l|l|l|}
\hline & $\begin{array}{l}\text { Commerc } \\
\text { ial } \\
\text { Uncoated }\end{array}$ & $\begin{array}{l}\text { Commerc } \\
\text { ial } \\
\text { Coated }\end{array}$ & $\begin{array}{l}\% 0.1 \\
\text { Uncoate } \\
\mathrm{d}\end{array}$ & $\begin{array}{l}\% 0.1 \\
\text { Coate } \\
\mathrm{d}\end{array}$ & $\begin{array}{l}\% 1 \\
\text { Uncoate } \\
\mathrm{d}\end{array}$ & $\begin{array}{l}\% 1 \\
\text { Coate } \\
\mathrm{d}\end{array}$ & $\begin{array}{l}\% 3 \\
\text { Uncoate } \\
\mathrm{d}\end{array}$ & $\begin{array}{l}\% 3 \\
\text { Coate } \\
\mathrm{d}\end{array}$ & $\begin{array}{l}\% 5 \\
\text { Uncoate } \\
\mathrm{d}\end{array}$ & $\begin{array}{l}\% 5 \\
\text { Coate } \\
\mathrm{d}\end{array}$ \\
\hline $\mathrm{L}_{1}$ & 93.43 & 93.65 & 93.59 & 93.95 & 93.60 & 93.83 & 93.06 & 92.76 & 91.59 & 92.47 \\
\hline $\mathrm{L}_{2}$ & 93.69 & 93.89 & 93.69 & 93.71 & 94.08 & 94.21 & 93.49 & 93.10 & 91.96 & 92.20 \\
\hline $\mathrm{L}_{3}$ & 93.57 & 93.81 & 94.10 & 92.71 & 93.88 & 94.14 & 93.44 & 92.58 & 92.22 & 92.45 \\
\hline $\mathrm{L}_{\mathrm{av}}$ & 93.56 & 93.78 & 93.79 & 93.46 & 93.85 & 94.06 & 93.33 & 92.81 & 91.92 & 92.37 \\
\hline $\mathrm{a}_{1}$ & -1.03 & -0.86 & -0.99 & -0.95 & -0.99 & -0.91 & -0.91 & -0.79 & -0.46 & -0.68 \\
\hline
\end{tabular}


International Advanced Research Journal in Science, Engineering and Technology

Vol. 6, Issue 2, February 2019

\begin{tabular}{|c|c|c|c|c|c|c|c|c|c|c|}
\hline$a_{2}$ & $\begin{array}{l}-0.82 \\
\end{array}$ & -0.92 & -0.81 & -0.92 & -0.87 & -0.79 & -1.05 & -0.94 & -0.45 & -0.52 \\
\hline$a_{3}$ & -0.89 & -0.9 & -0.88 & -0.92 & -1.04 & -0.91 & -1.07 & -1.03 & -0.71 & -0.65 \\
\hline $\mathrm{a}_{\mathrm{av}}$ & -0.91 & -0.89 & -0.89 & -0.93 & -0.97 & -0.87 & -1.01 & -0.92 & -0.54 & -0.62 \\
\hline$b_{1}$ & 2.15 & 2.26 & 1.95 & 2.15 & 2.29 & 2.16 & 2.52 & 2.87 & 2.34 & 2.15 \\
\hline $\mathrm{b}_{2}$ & 2.34 & 2.29 & 2.28 & 2.63 & 2.50 & 2.25 & 2.54 & 2.87 & 2.10 & 2.18 \\
\hline $\mathrm{b}_{3}$ & 2.23 & 2.06 & 2.13 & 2.19 & 2.27 & 2.09 & 2.62 & 3.17 & 1.90 & 2.19 \\
\hline $\mathrm{b}_{\mathrm{av}}$ & 2.24 & 2.20 & 2.12 & 2.32 & 2.35 & 2.17 & 2.56 & 2.97 & 2.11 & 2.17 \\
\hline$\Delta \mathrm{L}_{\mathrm{a}}$ & \multicolumn{2}{|l|}{+0.22} & \multicolumn{2}{|c|}{-0.33} & \multicolumn{2}{|c|}{+0.21} & \multicolumn{2}{|c|}{-0.52} & \multicolumn{2}{|c|}{+0.45} \\
\hline$\Delta \mathrm{a}_{\mathrm{av}}$ & \multicolumn{2}{|l|}{+0.02} & \multicolumn{2}{|c|}{-0.04} & \multicolumn{2}{|c|}{+0.10} & \multicolumn{2}{|c|}{+0.09} & \multicolumn{2}{|c|}{-0.08} \\
\hline$\Delta \mathrm{b}_{\mathrm{av}}$ & \multicolumn{2}{|l|}{-0.04} & \multicolumn{2}{|c|}{+0.2} & \multicolumn{2}{|c|}{-0.18} & \multicolumn{2}{|c|}{+0.41} & \multicolumn{2}{|c|}{+0.06} \\
\hline$\Delta \mathrm{E}_{\mathrm{a}}$ & \multicolumn{2}{|l|}{0.22} & \multicolumn{2}{|c|}{0.39} & \multicolumn{2}{|c|}{0.29} & \multicolumn{2}{|c|}{0.66} & \multicolumn{2}{|c|}{0.46} \\
\hline
\end{tabular}

Table IIIII Contact Angle Values After The Uv Aging Test

\begin{tabular}{|c|c|c|c|c|c|c|c|c|c|c|}
\hline & $\begin{array}{l}\text { Commerc } \\
\text { ial } \\
\text { Uncoated }\end{array}$ & $\begin{array}{l}\text { Commerc } \\
\text { ial } \\
\text { Coated }\end{array}$ & $\begin{array}{l}\% 0.1 \\
\text { Uncoate } \\
\mathrm{d}\end{array}$ & $\begin{array}{l}\% 0.1 \\
\text { Coate } \\
\mathrm{d}\end{array}$ & $\begin{array}{l}\% 1 \\
\text { Uncoate } \\
\mathrm{d}\end{array}$ & $\begin{array}{l}\% 1 \\
\text { Coate } \\
\text { d }\end{array}$ & $\begin{array}{l}\% 3 \\
\text { Uncoate } \\
d\end{array}$ & $\begin{array}{l}\% 3 \\
\text { Coate } \\
\text { d }\end{array}$ & $\begin{array}{l}\% 5 \\
\text { Uncoate } \\
\mathrm{d}\end{array}$ & $\begin{array}{l}\% 5 \\
\text { Coate } \\
d\end{array}$ \\
\hline $\mathrm{L}_{1}$ & 93.99 & 94.25 & 94.29 & 94.48 & 94.42 & 94.43 & 94.19 & 93.69 & 92.45 & 92.81 \\
\hline $\mathrm{L}_{2}$ & 94.18 & 94.15 & 94.09 & 94.32 & 94.38 & 94.63 & 94.39 & 93.91 & 92.80 & 92.30 \\
\hline $\mathrm{L}_{3}$ & 94.01 & 94.43 & 94.72 & 94.29 & 94.43 & 94.60 & 94.43 & 93.91 & 93.29 & 92.81 \\
\hline $\mathrm{L}_{\mathrm{av}}$ & 94.06 & 94,28 & 94,37 & 94,36 & 94,41 & 94,55 & 94,34 & 93,84 & 92,85 & 92,64 \\
\hline$a_{1}$ & -0.53 & -0.64 & -0.69 & -0.70 & -0.79 & -0.75 & -0.71 & $\begin{array}{l}-0.61 \\
\end{array}$ & -0.41 & -0.31 \\
\hline$a_{2}$ & -0.59 & -0.56 & -0.64 & -0.69 & -0.78 & -0.87 & -0.87 & -0.71 & -0.33 & -0.46 \\
\hline$a_{3}$ & -0.46 & -0.80 & -0.82 & -0.64 & -0.83 & -0.84 & -0.85 & -0.70 & -0.45 & -0.42 \\
\hline $\mathrm{a}_{\mathrm{av}}$ & -0.53 & -0.67 & -0.72 & -0.68 & -0.8 & -0.82 & -0.81 & -0.67 & -0.40 & -0.40 \\
\hline $\mathrm{b}_{1}$ & 0.85 & 0.67 & 0.43 & 0.52 & 0.57 & 0.39 & 0.55 & 0.82 & 0.75 & 0.79 \\
\hline $\mathrm{b}_{2}$ & 0.68 & 0.69 & 0.49 & 0.62 & 0.62 & 0.41 & 0.53 & 0.81 & 0.66 & 0.87 \\
\hline $\mathrm{b}_{3}$ & 0.58 & 0.61 & 0.36 & 0.44 & 0.61 & 0.42 & 0.54 & 0.71 & 0.54 & 0.99 \\
\hline $\mathrm{b}_{\mathrm{av}}$ & 0.70 & 0.66 & 0.43 & 0.53 & 0.60 & 0.41 & 0.54 & 0.78 & 0.65 & 0.88 \\
\hline$\Delta \mathrm{L}_{\mathrm{a}}$ & \multicolumn{2}{|l|}{0.22} & \multicolumn{2}{|c|}{-0.01} & \multicolumn{2}{|c|}{0.14} & \multicolumn{2}{|c|}{-0.5} & \multicolumn{2}{|c|}{-0.21} \\
\hline$\Delta \mathrm{a}_{\mathrm{av}}$ & \multicolumn{2}{|l|}{-0.14} & \multicolumn{2}{|c|}{0.04} & \multicolumn{2}{|c|}{-0.02} & \multicolumn{2}{|c|}{0.14} & \multicolumn{2}{|c|}{0} \\
\hline$\Delta \mathrm{b}_{\mathrm{av}}$ & \multirow{2}{*}{\multicolumn{2}{|c|}{$\begin{array}{l}-0.04 \\
0.26\end{array}$}} & \multirow{2}{*}{\multicolumn{2}{|c|}{$\begin{array}{l}0.10 \\
0.11\end{array}$}} & \multirow{2}{*}{\multicolumn{2}{|c|}{$\begin{array}{r}-0.21 \\
0.25\end{array}$}} & \multirow{2}{*}{\multicolumn{2}{|c|}{$\begin{array}{l}0.23 \\
0.27\end{array}$}} & \multicolumn{2}{|c|}{0.13} \\
\hline$\Delta \mathrm{E}_{\mathrm{a}}$ & & & & & & & & & \multicolumn{2}{|c|}{0.25} \\
\hline
\end{tabular}

The $\Delta \mathrm{E}$ values were calculated of the coated, and uncoated parts of the marbles before, and after the 144 hour UV aging test. The results before the UV aging test show that the variations in both $\Delta \mathrm{a}$, and $\Delta \mathrm{b}$ values are very small and the $\Delta \mathrm{E}$ value for all samples is very much smaller than 5 , which indicates that the color change of the coated samples are not observable with the naked eye in all of the formulations[18]. Eventhough Manoudis et. al reported that the addition of silica nanoparticles into the PDMS matrix increased the lightness values of white marble surfaces a similar effect here wasn't seen [19]. Nevertheless, a and b components remained unaltered in both formulations.

After the UV aging test, the $\Delta \mathrm{E}$ value for all samples is still very small so for all of the samples, the color change was negligible. Nevertheless, there was a notable reduction in te $b$ values of both the uncoated and parts of all of the samples, which signified that all samples became less yellow as a result of the UV aging process.

\section{CONCLUSION}

The results show that the addition of silica nanoparticles with a primary particle size of 12 nm vastly improves the protective efficiency of the siloxane composition for marble substrates. The application of this modified composition on marble substrates render the treated surfaces hydrophobic with highly water repellent properties. The enhancement of the contact angle depends on the nanoparticle concentration. When the nanoparticle content is lower than \%1, the nanosilica protrusions cover a small amount of the surface. So the nanosilica particles enhance the contact angle only to a minor extent. At \%1 nanosilica content, however, the particles cover most of the surface and a two level hierarchy is 


\title{
International Advanced Research Journal in Science, Engineering and Technology
}

\author{
Vol. 6, Issue 2, February 2019
}

reached causing the contact angle to increase to $145^{\circ}$ to the highest value which renders its surface superhydrophobic. Similar effect is also seen in the $\% 3$ coating with a slight drop of the contact angle value. When $\% 5$ nanosilica is added, however, due to the large crack shaped cavities between the aggregates, the wetting regime changes from Cassie Baxter to Wenzel causing the drops to stick on the surface. In terms of colorimetric properties before and after the UV aging test, all samples display superior properties. In terms of humidity resistance, however, only the $\% 3 \mathrm{w} / \mathrm{w}$ coating retains its superhydrophobic property eventhough the $\% 1$, and 0.1 , and the commercial sample are also still hydrophobic.

\section{REFERENCES}

[1]. I. Özturk, “Alkoxysilanes Consolidation of Stone, and Earthen Building Materials,” M. Eng. Thesis, University of Pennsylvania, Philadelphia, PA, 1992.

[2]. Y. Luo, L. Xiao, X. Zhang, "Characterization of TEOS/PDMS/HA nanocomposites for application as consolidant/hydrophobic products on sandstones,”. J. Cult. Herit., 2014

[3]. E. K. Kim, J. Won, J. Do, S. D. Kim, Y.S. Kang. "Effects of silica nanoparticle and GPTMS addition on TEOS-based stone consolidants,". J. Cult. Herit. , vol. 10, pp. 214-221, 2010.

[4]. J. Zhao, H. Luo, L. Wang, W. Li, T. Zhou, B. Rong, "TEOS/PDMS -OH hybrid material for the consolidation of damaged pottery," Heritage Science, vol. 1, pp. 1-12, 2013.

[5]. R. Zarraga, J. Cervantes, C. Salazar-Hernandez, G. Wheeler, "Effect of the addition of hydroxyl-terminated polydimethysiloxane to TEOSbased stone consolidants," J . Cult. Herit. , vol. 11, pp. 138-144, 2010.

[6]. P. Maravelaki-Kalaitzaki, N. Kalithrakas-Kontos, Z. Agioutantis, S. Maurigiannakis, D. Korakaki, “A comparative study of porous limestones treated with silicon-based strengthening agents," Progress in Organic Coatings, vol. 62, pp. 49-60, 2008

[7]. C. Salazar-Hernandez, M. J.P. Alquiza, P. Salgado, J. Cervantes, "TEOS- colloidal- PDMS-OH hybrid formulation used for stone consolidation,". Applied Organometallic Chemistry, vol. 24, pp. 481-488, 2010.

[8]. D. Li, F. Xu, Z. Liu, J. Zhu, Q. Zhang, L. Shao, "The effect of adding PDMS-OH and silica nanoparticles on sol-gel properties and effectiveness in stone protection,” Appl. Surf. Sci., vol. 266, pp. 368-374, 2013.

[9]. P. N. Manoudis, I. Karapanagiotis, A. Tsakalof, I. Zuburtikudis, B. Kolinkeova, and C. Panayiotou, "Surface Properties of Superhydrophobic Coatings for Stone Protection," Journal of Nano Research, vol. 8, pp. 23-33, 2009.

[10]. Maria, J. Mosquera, Desiree M. de los Santos, and Teresa Rivas, "Surfactant-synthesized Ormosils with Application to Stone Restoration," Langmuir, vol. 26, pp. 6737-6745, 2010.

[11]. P.N.Manoudis, I.Karapanagiotis, A.Tsakalof, I.Zuburtikudis, C.Panayiotou, "Superhydrophobic Composite films produced on Various Substrates," Langmuir, vol. 24, pp. 11225-11232, 2008.

[12]. CIE, Publication CIE n\&ordm 152, Colorimetry, 2nd ed., Central Bureau of the CIE, Vienna, 1986

[13]. Paints and Varnishes- Determination of resistance to humidity-Part 2:Condensation (in cabinet exposure with heated water reservoir) Specification, ISO Std. 6270-2, 2017.

[14]. A.B.D. Cassie, S. Baxter, Trans. Faraday Soc. 40 (1944) 546

[15]. A. Lafuma, D. Que're', "Superhydrophobic states," Nat. Mater., vol. 2, pp. 457-460, 2003

[16]. K. A. Wier, T. J. McCarthy, "Condensation on Ultrahydrophobic Surfaces and Its Effect on Droplet Mobility: Ultrahydrophobic Surfaces are not Always Water Repellent,” Langmuir, vol. 22, pp. 2433-2436, 2006.

[17]. L. de Ferri, P.P. Lottici, A. Lorenzi, A. Montenero, E. Salvioli-Mariani, "Study of silica nanoparticles- polysiloxane hydrophobic treatments for stone-based monument protection," J. Cult. Herit., vol. 12, pp. 356-363, 2011.

[18]. M. Favaro, R. Mendichi, F. Ossola, S. Simon, P. Tomasin, P. A. Vigato, "Evaluation of polymers for conservation treatments of outdoor exposed stone monuments. Part II: Photo-oxidative and salt induced weathering of acrylic- silicone mixtures, 1. Polym. Deg. Stab. , vol. 92, pp. 335-351, 2007.

[19]. P. Manoudis, A. Tsakalof, , I. Karapanogiotis I. Zuburtikudis, C. Panayiotou,"Fabrication of super hydrophobic surfaces for enhanced stone protection," Surf . Coat. Tech., vol. 203, pp. 1322-1328, 2009 